\title{
ENRAIZAMENTO DE MINIESTACAS APICAIS, INTERMEDIÁRIAS E BASAIS EM CLONES DE Eucalyptus benthamii
}

\author{
Cristiane Carla Benin ${ }^{1}$, Fabiana Schmidt Bandeira Peres ${ }^{2}$, Flávio Augusto de Oliveira Garcia ${ }^{3}$ \\ ${ }^{1}$ Eng $^{\mathrm{a}}$. Florestal, Mestranda em Ciências Florestais, UNICENTRO, Irati, PR, Brasil - cristianebenin@ hotmail.com \\ ${ }^{2}$ Eng $^{\mathrm{a}}$. Florestal. Dra., Depto. de Engenharia Florestal, UNICENTRO, Irati, PR, Brasil - fsbandeiraperes@ hotmail.com \\ ${ }^{3}$ Eng. Florestal. Dr., Depto. de Engenharia Florestal, UNICENTRO, Irati, PR, Brasil - msfa_garcia @ yahoo.com.br
}

Recebido para publicação: 17/08/2012 - Aceito para publicação: 02/07/2013

\begin{abstract}
Resumo
Este trabalho teve como objetivo avaliar o enraizamento de miniestacas apicais, intermediárias e basais de Eucalyptus benthamii Maiden et Cambage. As miniestacas utilizadas foram coletadas de minicepas estabelecidas a partir de mudas de origem seminal. O experimento foi conduzido no delineamento inteiramente casualizado, em arranjo fatorial $4 \times 3$, sendo os fatores constituídos por quatro clones de E. benthamii (C50, C51, C52 e C53) e três tipos de miniestacas, confeccionadas das porções apical, intermediária e basal das brotações. Avaliou-se a sobrevivência e o enraizamento das mudas aos 45 dias de idade, em casa de sombra, e aos 90 dias em fase de pleno sol. Avaliou-se ainda a altura das mudas aos 90 dias de idade. Ao final das avaliações, o clone C52 se destacou dos demais em termos de sobrevivência, enraizamento e crescimento em altura. Na fase de pleno sol, quando as mudas já haviam completado o ciclo de desenvolvimento, a miniestaca apical comprovou ser o tipo de propágulo com maior aptidão ao enraizamento entre todos os clones avaliados.

Palavras-chave: Miniestaquia; tipos de estaca; propagação clonal.
\end{abstract}

\begin{abstract}
Rooting of apical, intermediate and basal minicuttings in clones of Eucalyptus benthamii. This study aimed to evaluate the rooting of apical, intermediate and basal ministumps of Eucalyptus benthamii Maiden et Cambage. The minicuttings were collected from ministumps originated from seedlings. The experiment was conducted in a completely randomized design, in a 4x3 factorial arrangement with factors consisting of four clones of E. benthamii (C50, C51, C52 e C53) and three types of cuttings (apical, intermediate and basal). The survival and rooting were evaluated with 45 days in shadow house, and 90 days in the full sun stage. In the end of the evaluations, the clone C52 proved to be better in survival, rooting and height growth. In full sun stage, when the seedlings completed the development cycle, the apical minicutting proved to be the kind of propagules with grater aptitude on rooting when compared with the others clones.

Keywords: Minicutting; types of cuttings; clonal propagation.
\end{abstract}

\section{INTRODUÇÃO}

A silvicultura no Brasil tem assumido posição de destaque no contexto da economia nacional, tornando-se uma atividade cada vez mais praticada no setor agrário nacional pela rentabilidade apresentada. As espécies do gênero Eucalyptus assumiram a preferência dos investidores, devido às facilidades quanto à adaptação, rápido crescimento e a versatilidade no uso da madeira. No entanto, nas regiões mais frias, como o sul do Brasil, os cultivos limitam-se às espécies adaptadas, como o Eucalyptus benthamii, com capacidade de suportar temperaturas extremamente baixas, aliada ao potencial energético (PALUDZYSZYN FILHO et al., 2006).

O desenvolvimento de tecnologias efetivas na propagação clonal dessa espécie tem se mostrado de fundamental importância, visto que a propagação seminífera é limitada pelo elevado custo de aquisição de sementes de procedência geneticamente melhorada, o que dificulta a formação de mudas de qualidade. No setor florestal, justifica-se o uso da propagação clonal na produção de mudas de espécies de interesse quando há limitações na produção seminal (XAVIER et al., 2003a) e também pelas vantagens oferecidas 
pelo processo, como ganhos em homogeneidade e produtividade (BRONDANI et al., 2009).

Atualmente, a miniestaquia é a técnica de propagação vegetativa mais utilizada pelas empresas do setor florestal brasileiro, visando à produção de mudas clonais de Eucalyptus sp. Dentre os principais ganhos obtidos, a miniestaquia possibilitou a otimização da taxa de enraizamento, redução da área do jardim clonal, uniformidade das miniestacas, qualidade das mudas clonais, diversificação no sistema de implantação do minijardim clonal (BRONDANI et al., 2010; FERRIANI et al., 2010; ALFENAS et al., 2004), redução do tempo de enraizamento e aclimatização das mudas (XAVIER et al., 2003a), assim como a facilidade operacional e econômica oferecida pela técnica no processo produtivo (XAVIER; WENDLING, 1998).

Estudos avaliando a eficiência da miniestaquia têm demonstrado resultados positivos quanto ao enraizamento, sobrevivência de miniestacas e emissão de novos propágulos em espécies de eucaliptos subtropicais, como Eucalyptus dunnii Maiden (SOUZA JÚNIOR; WENDLING, 2003), clones híbridos de Eucalyptus urophylla x Eucalyptus globulus (BORGES et al., 2011) e de Eucalyptus grandis x Eucalyptus globulus (OLIVEIRA et al., 2012). Para o Eucalyptus benthamii, os registros de uso da miniestaquia ainda são escassos e com índices de enraizamento pouco expressivos. Graça et al. (1999) avaliaram o enraizamento adventício dessa espécie utilizando a técnica de estaquia convencional. O maior índice de enraizamento observado foi de apenas $30 \%$, demonstrando a dificuldade de propagação vegetativa de E. benthamii. Brondani et al. (2008) apontaram o potencial de aplicação dessa técnica na propagação clonal de $E$. benthamii mediante a realização de alguns ajustes, justificados pelo baixo percentual médio de enraizamento (43\%) observado nos clones avaliados.

Mais recentemente, o emprego da miniestaquia foi reportado em clones híbridos de E. benthamii x E. dunnii, em que o enraizamento das miniestacas não ultrapassou 55\% (BRONDANI et al., 2010a; BRONDANI et al., 2010b). O mesmo comportamento foi relatado em outro estudo com clones híbridos de $E$. benthamii x $E$. dunnii utilizando-se diferentes substratos de enraizamento, em que os percentuais médios de enraizamento obtidos foram inferiores a 55\% (KRATZ et al., 2012). Dessa forma, apesar do potencial da miniestaquia para a espécie, a dificuldade de enraizamento constatado pelos baixos percentuais limita a produção de mudas clonais nos viveiros e consequentemente o aumento da área clonal cultivada.

Dentre os fatores que afetam o sucesso da propagação via miniestaquia, merece destaque o tipo de miniestaca utilizado. Na propagação vegetativa de espécies lenhosas por enraizamento adventício, a estaca caulinar tem sido o tipo de propágulo mais empregado (XAVIER et al., 2009). Contudo, a consistência dos tecidos e a posição do ramo dos quais os propágulos são retirados podem acarretar respostas diferenciadas no processo de enraizamento adventício (FACHINELLO et al., 2005). Tal fato está associado ao ciclo de desenvolvimento das plantas e à maturação fisiológica dos tecidos com o envelhecimento destas (HIGASHI et al., 2000). Nesse sentido, a perda de vigor, lignificação dos tecidos e os efeitos negativos do envelhecimento ontogenético tornam-se mais pronunciados em miniestacas das porções basais e intermediárias dos ramos, as quais são classificadas como lenhosas e semilenhosas, respectivamente (XAVIER; WENDLING, 2001). Assim, em viveiros florestais, é prática já estabelecida o uso de miniestacas apicais, pois elas tendem a formar raízes com maior facilidade, em virtude de possuírem os meristemas, os quais são locais de síntese natural de auxinas nas plantas (HARTMANN et al., 2002; TAIZ; ZEIGER, 2004). Segundo Borges et al. (2011), as miniestacas apicais conferem vantagens se comparadas às intermediárias, em razão de apresentarem menor grau de lignificação de seus tecidos.

Todavia, tratando-se de uma espécie pouco conhecida da silvicultura brasileira e com escassez de informações, é importante avaliar se o comportamento das miniestacas de E. benthamii segue esse padrão com melhor enraizamento das estacas apicais. Há espécies arbóreas, como Calophyllum brasiliense, em que o uso de miniestacas apicais e intermediárias não influenciou no enraizamento dos propágulos (SILVA et al., 2010). Ferreira et al. (2012) observaram que miniestacas apicais, intermediárias e basais mostraram-se aptas à propagação via miniestaquia de Toona ciliata F. Muell, apresentando enraizamento superior a 90\% para os três tipos de propágulos avaliados. Isso implica maior aproveitamento das brotações colhidas e otimização do processo.

Diante do exposto e da necessidade de aprimoramento da técnica de miniestaquia para a espécie em questão, este trabalho teve por objetivo avaliar o potencial de enraizamento de miniestacas apicais, intermediárias e basais, em quatro clones de E. benthamii, estabelecidos a partir de material juvenil. 


\section{MATERIAL E MÉTODOS}

O presente trabalho foi conduzido no período de março a junho de 2011, no Viveiro de Pesquisas do Departamento de Engenharia Florestal da Universidade Estadual do Centro-Oeste, em Irati, Paraná, situada a $25^{\circ} 27^{\prime} 56^{\prime \prime}$ de latitude S e $50^{\circ} 37^{\prime} 51^{\prime \prime}$ de longitude W, com altitude média de 812 metros. O clima da região, de acordo com o Sistema Internacional de Köppen, é do tipo Cfb (clima subtropical úmido), caracterizado pela ocorrência de geadas frequentes no inverno, apresentando precipitação média anual de $193,97 \mathrm{~mm}$ e temperatura média anual de $24,2{ }^{\circ} \mathrm{C}$ no verão e de $11{ }^{\circ} \mathrm{C}$ no inverno (PREFEITURA MUNICIPAL DE IRATI, 2011).

Foram utilizadas miniestacas de quatro clones de E. benthamii (C50, C51, C52 e C53), as quais foram coletadas de minicepas estabelecidas a partir de mudas de origem seminal, cedidas pela empresa Golden Tree Reflorestadora Ltda.

Para o estabelecimento das minicepas, mudas com aproximadamente 120 dias de idade foram transferidas para vasos com capacidade de $3 \mathrm{~L}$ contendo substrato comercial à base de turfa e vermiculita. As matrizes foram submetidas à poda de formação, em que se retirou a porção apical da muda a uma altura de $10 \mathrm{~cm}$ da base, com o objetivo de formação das minicepas. As minicepas foram dispostas em canteiros suspensos com sombreamento de 50\%. A nutrição mineral utilizada foi realizada pela aplicação semanal de $20 \mathrm{~mL}$ por minicepa de solução nutritiva composta de nitrato de cálcio $\left(0,8 \mathrm{~g} \cdot \mathrm{L}^{-1}\right)$, nitrato de potássio $\left(0,8\right.$ g.L $\left.\mathrm{L}^{-1}\right)$, monoamônio fosfato $\left(2,2 \mathrm{~g} . \mathrm{L}^{-1}\right)$, ETDA dissódico $\left(0,4 \mathrm{~g} \cdot \mathrm{L}^{-1}\right)$, ácido bórico $\left(0,04\right.$ g.L $\left.\mathrm{L}^{-1}\right)$ e complexo vitamínico $\left(0,04 \mathrm{~g} . \mathrm{L}^{-1}\right)$, intercalando-se com a aplicação de $20 \mathrm{~mL}$ por minicepa de solução de NPK (4-14-08).

A coleta das brotações no minijardim clonal foi realizada no período matutino. O período compreendido entre a coleta das miniestacas e o estaqueamento em substrato foi sempre inferior a 30 minutos, a fim de evitar a evapotranspiração excessiva das miniestacas e minimizar o estresse hídrico dos propágulos. Para a coleta, utilizou-se tesoura de poda previamente desinfestada em álcool $70 \%$ (v/v). Após a coleta, as miniestacas foram acondicionadas em caixas de isopor com água, de modo a manter as condições de turgescência do material vegetal, conforme metodologia adaptada de XAVIER et al. (2009).

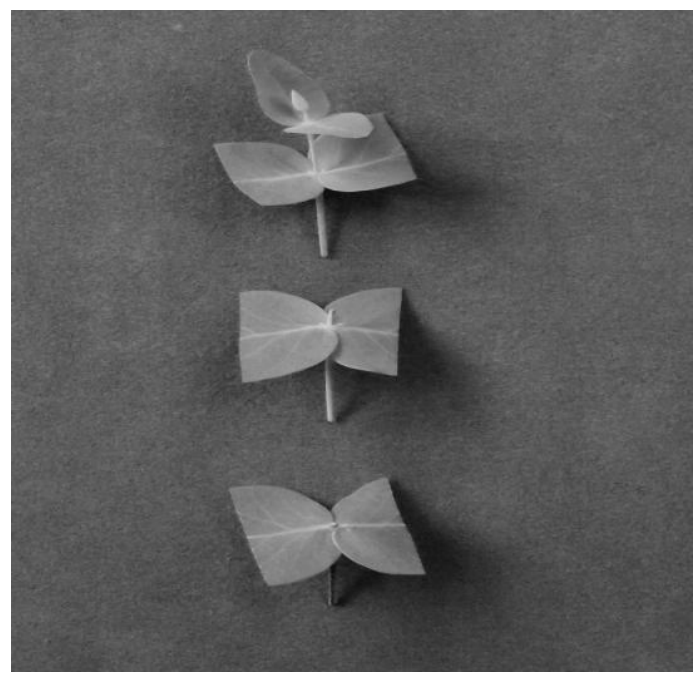

Figura 1. Miniestacas de Eucalyptus benthamii com 3 a $4 \mathrm{~cm}$ de comprimento e área foliar reduzida a $50 \%$, obtidas a partir de minicepas de origem seminal. (A) Miniestaca proveniente da porção apical do ramo; (I) Miniestaca proveniente da porção intermediária do ramo; (B) Miniestaca proveniente da porção basal do ramo. Barra $=1 \mathrm{~cm}$.

Figure 1. Minicuttings of Eucalyptus benthamii with $3-4 \mathrm{~cm}$ length and foliar area reduced to 50\%, obtained from ministumps of seedlings. (A) minicutting obtained of apical part of the branch; (I) minicutting obtained of intermediate part of the branch; (B) minicutting obtained of basal part of the branch. $\mathrm{Bar}=1 \mathrm{~cm}$. 
As miniestacas foram retiradas de diferentes posições nas brotações: ápice, parte intermediária e base. Em seguida foram confeccionadas com dimensões entre 3 e $4 \mathrm{~cm}$, contendo de um a dois pares de folhas, sendo a área foliar reduzida a 50\% de seu tamanho original (Figura 1).

\section{RESULTADOS E DISCUSSÃO}

Não foi observada interação significativa entre os clones e os tipos de miniestacas para a sobrevivência e enraizamento avaliados aos 45 e 90 dias de idade ( $p>0.05$ ).

$\mathrm{Na}$ avaliação de sobrevivência aos 45 dias de idade, não houve efeito significativo para os clones estudados, apenas em relação aos tipos de miniestacas ( p <0,05). Já aos 90 dias de idade, a sobrevivência, o enraizamento e o crescimento em altura foram influenciados pelos diferentes clones e pelos tipos de miniestacas $(\mathrm{p}<0,05)$.

Os percentuais de sobrevivência para miniestacas apicais e intermediárias foram superiores a $80 \%$. As miniestacas intermediárias mostraram-se significativamente superiores $(91,66 \%)$ em relação às basais $(64,58 \%)$, no entanto não diferiram das miniestacas oriundas da parte apical das brotações, as quais apresentaram $81,33 \%$ de sobrevivência ao final de 45 dias (Tabela 1).

Tabela 1. Sobrevivência (SOB45 e SOB90), enraizamento (ENR90) e altura média (H90) de miniestacas apicais, intermediárias e basais de clones de E. benthamii.

Table 1. Survival (SOB45 and SOB90), rooting (ENR90) and average height (H90) of apical, intermediate and basal minicuttings of clones of E. benthamii.

\begin{tabular}{lcccc}
\hline Tipo de miniestaca & SOB45 $(\%)$ & SOB90(\%) & ENR90(\%) & H90 (cm) \\
\hline Apical & $81,33^{\mathrm{ab}}$ & $68,75^{\mathrm{a}}$ & $56,24^{\mathrm{a}}$ & $3,97^{\mathrm{a}}$ \\
Intermediária & $91,66^{\mathrm{a}}$ & $45,83^{\mathrm{a}}$ & $18,74^{\mathrm{b}}$ & $2,21^{\mathrm{b}}$ \\
Basal & $64,58^{\mathrm{b}}$ & $18,74^{\mathrm{b}}$ & $14,58^{\mathrm{b}}$ & $1,26^{\mathrm{b}}$ \\
\hline
\end{tabular}

Médias seguidas por uma mesma letra não diferem estatisticamente, pelo teste de Tukey ao nível de 5\% de probabilidade de erro. Averages followed by the same letter don't differ statistically, considering the test of Tukey at 5\% of probability.

Estacas obtidas das porções mais tenras das brotações apresentam maior juvenilidade fisiológica, no entanto, dada à sua consistência, possuem baixa resistência às condições ambientais adversas. Por sua vez, estacas lenhosas apresentam maior capacidade de sobrevivência, considerando o maior grau de lignificação dos tecidos (XAVIER et al., 2009). Aos 90 dias de idade, miniestacas oriundas dos terços apical $(68,75 \%)$ e intermediário $(45,83 \%)$ apresentaram sobrevivência significativamente superior às basais $(18,74 \%)$ (Tabela 1$)$.

Nessa fase, a drástica redução do índice de sobrevivência observado para as miniestacas da porção basal pode ser atribuído às mudanças advindas do novo ambiente, onde a umidade deixa de ser controlada, e também devido à maior incidência de luz. Nessa condição, provavelmente, as miniestacas passaram a sofrer maior efeito da variação ambiental, e esses fatores podem acarretar em estresse e morte das mesmas (OLIVEIRA et al., 2012; BRONDANI et al., 2010a; BRONDANI et al., 2010b, WENDLING; XAVIER, 2005), principalmente nesse tipo de propágulo, em que a concentração de fitorreguladores endógenos é menor e a predisposição à formação de raízes adventícias pode ser afetada negativamente (TAIZ; ZEIGER, 2004).

Quanto ao enraizamento, miniestacas obtidas da porção apical apresentaram percentual médio significativamente superior $(56,24 \%)$ ao das miniestacas intermediárias $(18,74 \%)$ e basais $(14,58 \%)$ aos 90 dias de idade, indicando ser este o tipo de propágulo com maior predisposição ao enraizamento adventício para os clones avaliados (Tabela 1). A mesma tendência foi observada para a altura das mudas, sendo que o propágulo oriundo da porção apical da brotação acarretou em mudas de maior crescimento médio $(3,97 \mathrm{~cm})$, enquanto as miniestacas obtidas das regiões intermediária $(2,21 \mathrm{~cm})$ e basal $(1,26 \mathrm{~cm})$ das brotações apresentaram crescimento pouco expressivo, possivelmente atribuído às condições fisiológicas e ao maior grau de lignificação dos tecidos desses propágulos.

Estudos conduzidos com outras espécies de eucaliptos subtropicais têm apontado a maior predisposição ao enraizamento de miniestacas apicais comparativamente àquelas obtidas da porção intermediária das brotações, conforme observado em clones híbridos de E. globulus (OLIVEIRA et al., 2012; BORGES et al., 2011). O uso de miniestacas apicais também refletiu em maior crescimento do 
diâmetro do colo e altura das mudas de alguns dos clones avaliados (OLIVEIRA et al., 2012). Em outra espécie exótica, como o Pinus taeda, miniestacas da porção apical das brotações também apresentaram elevada capacidade de enraizamento (ANDREJOW; HIGA, 2009).

Em relação a espécies florestais de outras famílias botânicas, estudos comparando diferentes tipos de propágulos demostraram que miniestacas apicais proporcionaram ganhos expressivos no enraizamento das mudas para Cedrella fissilis (84,3\%) (XAVIER et al., 2003a), Cariniana estrellensis (71\%) (CASTRO, 2011) e Piptadenia gonoacantha (100\%) (HERNÁNDES et al., 2012). Segundo HARTMANN et al. (2002), a utilização de miniestacas apicais pode conferir vantagens ao processo de propagação vegetativa, tendo em vista que as porções apicais do ramo contêm os meristemas, os quais concentram elevados níveis de auxinas, essenciais à formação de raízes adventícias.

A variação observada entre os tipos de miniestacas estudados pode ainda ser atribuída à consistência dos propágulos utilizados, visto que miniestacas lenhosas, retiradas da porção basal dos ramos, possuem menor habilidade em enraizar, devido ao maior grau de maturação fisiológica e lignificação dos tecidos (XAVIER et al., 2009; DAVIS et al., 1986).

Ao fim da fase de aclimatização, o clone C52 apresentou melhor desempenho tanto para a sobrevivência quanto para enraizamento e altura das mudas clonais (Tabela 2). Esse resultado pode estar relacionado com a variabilidade genética das minicepas, considerando o fato de serem de origem seminal, visto que as condições genéticas, nutricionais e fisiológicas da matriz doadora de propágulos podem conferir respostas diferenciadas à propagação vegetativa (HARTMANN et al., 2002; XAVIER et al., 2009; BORGES et al., 2011).

Tabela 2. Sobrevivência (SOB90), enraizamento (ENR90) e altura média (H90) de diferentes clones de E. benthamii (C50, C51, C52 e C53) avaliadas aos 90 dias de idade.

Table 2. Survival (SOB90), rooting (ENR90) and average height (H90) of different clones of $E$. benthamii (C50, C51, C52 e C53) evaluated at 90 days.

\begin{tabular}{lccc}
\hline CLONES & SOB90 (\%) & ENR90 (\%) & H90 (cm) \\
\hline C50 & $30,55^{\mathrm{b}}$ & $19,44^{\mathrm{b}}$ & $2,04^{\mathrm{b}}$ \\
C51 & $30,55^{\mathrm{b}}$ & $16,66^{\mathrm{b}}$ & $2,02^{\mathrm{b}}$ \\
C52 & $77,77^{\mathrm{a}}$ & $61,11^{\mathrm{a}}$ & $4,35^{\mathrm{a}}$ \\
C53 & $38,88^{\mathrm{b}}$ & $22,22^{\mathrm{b}}$ & $1,52^{\mathrm{b}}$ \\
\hline
\end{tabular}

Médias seguidas por uma mesma letra não diferem estatisticamente, pelo teste de Tukey ao nível de 5\% de probabilidade de erro. Averages followed by the same letter don't differ statistically, considering the test of Tukey at $5 \%$ of probability.

\section{CONCLUSÕES}

- A miniestaquia a partir de material juvenil apresentou potencial de aplicação como estratégia de propagação clonal de E. benthamii, obtendo-se maiores ganhos no processo ao se utilizarem miniestacas apicais.

- Houve variabilidade de resposta entre os genótipos avaliados, com o clone C52 apresentando melhor desempenho quanto à sobrevivência e enraizamento das mudas clonais.

\section{AGRADECIMENTO}

À Empresa Golden Tree Reflorestadora Ltda., pela cessão do material genético utilizado na condução dos experimentos.

\section{REFERÊNCIAS}

ALFENAS, A. C.; ZAUZA, E. A. V.; MAFIA, R. G.; ASSIS, T. F. de. Clonagem e doenças do eucalipto. Viçosa: Editora UFV, 2004. 442 p.

ANDREJOW, G. M. P.; HIGA, A. R. Potencial de enraizamento de miniestacas de Pinus Taeda L. provenientes de brotação apical de mudas jovens. Revista Floresta, v. 39, n. 4, p. 897 - 903, 2009. 
BORGES, S. R.; XAVIER, A.; OLIVEIRA, L. S. de; MELO, L. A. de; ROSADO, A. M. Enraizamento de miniestacas de clones híbridos de Eucalyptus globulus. Revista Árvore, v. 35, n. 3, p. 425 - 434, 2011.

BRONDANI, E. G.; WENDLING, I.; ARAÚJO, M. A. de; PIRES, P. P. Ácido indolbutírico em gel para o enraizamento de miniestacas de E. benthamii Maiden e E. dunni Maiden. Scientia Agraria, v. 9, n. 2, p. $153-158,2008$.

BRONDANI, E. G.; WENDLING, I.; DUTRA, L. F.; GROSSI, F. Propagação vegetativa de E. benthamii x E. dunnii por miniestaquia. Colombo-PR: Embrapa Florestas, 2009. 42 p. (Embrapa Florestas, Documentos, 183).

BRONDANI, E. G.; GROSSI, F.; WENDLING, I.; DUTRA, L. F.; ARAÚJO, M. A. de. Aplicação de IBA para o enraizamento de miniestacas de E. benthamii Maiden e E. dunnii Maiden. Acta Scientiarum Agronomy, v. 32, n. 4, p. 667 - 674, 2010a.

BRONDANI, E. G.; WENDLING, I.; GROSSI, F.; DUTRA, L. F.; ARAÚJO, M. A. de. Miniestaquia de Eucalyptus benthamii $\times$ Eucalyptus dunnii: sobrevivência e enraizamento de miniestacas em função das coletas e estações do ano. Ciência Florestal, v. 20, n. 3, p. 453 - 465, 2010 b.

CASTRO, W. H. Propagação vegetativa do jequitibá-rosa (Cariniana estrellensis) Raddi-Kuntze e do pau-jacaré (Piptadenia gonoacantha) Mart. Macbr por estaquia. 73f. Dissertação (Mestrado em Ciência Florestal) - UFV. Viçosa, 2011.

DAVIS T. D.; HAISSIG, B. E.; SANKHLA, N. Adventitious root formation in cuttings. Oregon: Dioscorides Press, 315 p. 1986.

GRAÇA, M. E. C.; SHIMIZU, J. Y.; TAVARES, F. R. Capacidade de rebrota e de enraizamento de Eucalyptus benthamii. Boletim de Pesquisa Florestal, Colombo-PR, n. 39, p. 135 - 138, 1999.

FACHINELLO J. C.; HOFFMANN, A.; NACHTIGAL, J. C. Propagação de plantas frutíferas. Embrapa. Informação Tecnológica. Brasília, DF. 221 p. 2005.

FERREIRA, D. de A.; BARROSO, D. G.; SILVA, M. S. A. da; SOUZA, J. S. de; FREITAS, T. A. S. de; CARNEIRO, J. G. de A. Influência da posição das miniestacas na qualidade de mudas de cedro australiano e no seu desempenho inicial e no pós-plantio. Ciência Florestal, v. 22, n. 4, p. 715 - 723, 2012.

FERRIANI, A. P.; ZUFFELLATO-RIBAS, K. C.; WENDLING, I. Miniestaquia aplicada a espécies florestais. Revista Agro@mbiente On-line, v. 4, n. 2, p. 102 - 109, 2010. Disponível em: <http://ufrr.br/revista/index.php/agroambiente/search/authors>. Acesso em: 08/10/2011.

HARTMANN, H. T.; KESTER, D. E.; DAVIES JUNIOR, F. T.; GENEVE. R. L. Plant propagation: principles and practices. 7 ed. New Jersey: Prentice-Hall, 2002. 880 p.

HERNÁNDES, W.; XAVIER, A.; PAIVA, A. N de. Propagação vegetativa de pau-jacaré (Piptadenia gonoacantha (MART.) MACBR.) por estaquia. Revista Árvore, v. 36, n. 5, p. 813 - 823, 2012.

HIGASHI, E. N.; SILVEIRA, R. L. V. de A.; GONÇALVES, A. N. Propagação vegetativa de Eucalyptus: princípios básicos e sua evolução no Brasil. IPEF: 2000. Circular Técnica n. 192. 14 p. ESALQ/USP.

KRATZ, D.; WENDLING, I.; PIRES, P. P. Miniestaquia de Eucalyptus benthamii x Eucalyptus dunni em substratos a base de casca de arroz carbonizada. Scientia Forestalis, v. 40, n. 96, p. 547 - 556, 2012.

OLIVEIRA, L. S. de; XAVIER, A.; DIAS, P. C.; CORREIA, A. C. G.; BORGES, S. R.; TAKAHASHI, E. K.; PAIVA, H. N. de. Enraizamento de miniestacas e microestacas de clones de Eucalyptus urophylla $\mathrm{x}$ E. globulus. Scientia Forestalis, v. 40, n. 96, p. 507 - 516, 2012.

PALUDZYSZYN FILHO, E.; SANTO, P. E. T.; FERREIRA, C. A. Eucaliptos indicados para plantio no estado do Paraná. Colombo-PR: Embrapa Florestas, 2006. 45 p. (Embrapa Florestas, Documentos, 129).

PREFEITURA MUNICIPAL DE IRATI. Disponível em: <http://www.irati.pr.gov.br/municipio/clima. asp>. Acesso em: 11/06/2011. 
SOUZA JÚNIOR, L. de. ; WENDLING, I. Propagação vegetativa de Eucalyptus dunnii via miniestaquia de material juvenil. Boletim de Pesquisa Florestal, Colombo, PR, n. 46 p. 21 - 30, 2003.

SILVA, R. L. da; OLIVEIRA, M. L. de; MONTE, M. A.; XAVIER, A. Propagação clonal de guanandi (Calophyllum brasiliense) por miniestaquia. Agronomía Costarricense, v. 34, n. 1, p. 99 - 104, 2010.

TAIZ, L.; ZEIGER, E. Fisiologia vegetal. São Paulo: Limed, 2004, 719 p.

WENDLING, I.; XAVIER, A. Influência da miniestaquia seriada no vigor radicular de clones de Eucalyptus grandis. Revista Árvore, v. 29, n. 5, p. 681 - 689, 2005.

XAVIER, A.; WENDLING, I. Miniestaquia na clonagem de Eucalyptus. Viçosa: SIF, 1998. 10p. (Informativo Técnico SIF, 11).

XAVIER, A.; WENDLING, I. Gradiente de maturação e rejuvenescimento aplicado em espécies florestais. Revista Floresta e Ambiente, v. 8, n. 1, p. 187 - 194, 2001.

XAVIER, A.; SANTOS, G. A.; OLIVEIRA, M. L. Enraizamento de miniestaca caulinar e foliar na propagação vegetativa de cedro-rosa (Cedrela fissilis Vell.). Revista Árvore, v. 27, n. 3, p. 351 - 356, 2003 a.

XAVIER, A.; WENDLING, I.; DA SILVA, R. L. Silvicultura clonal: princípios e técnicas. Viçosa, MG: Editora UFV, 2009. 272 p. 
FLORESTA, Curitiba, PR, v. 43, n. 3, p. 421 - 428, jul. / set. 2013. Benin, C. C.; Peres, F. S. B.; Garcia, F. A. de O. 